\title{
Knowledge and Attitudes of Pregnant Women Regarding Breastfeeding
}

\author{
Hamdia M. Ahmed ${ }^{1 *}$, Safyia S. Piro ${ }^{2}$ \\ ${ }^{1}$ Department of Midwifery, College of Health Sciences, Hawler Medical University, Erbil, Kurdistan Region, Iraq, ${ }^{2}$ College of the Nursing, \\ University of Duhok, Duhok, Kurdistan Region, Iraq.
}

\begin{abstract}
${ }^{*}$ Correspondence author: Hamdia M. Ahmed,

Deanship, College of Health Sciences, Hawler Medical University, Erbil, Kurdistan Region, Iraq.

Phone: 009647504478625.

E-mail: hamdia.ahme@hmu. edu.krd
\end{abstract}

\begin{tabular}{l} 
Received: 02 August 2019 \\
Accepted: 17 November \\
2019 \\
Published: 01 December \\
2019 \\
\hline DOI \\
10.25156/ptj.v9n2y2019.pp55-62
\end{tabular}

\section{A B S T R A C T}

Inadequate knowledge or inappropriate attitude about breastfeeding may lead to undesirable consequences. This study assessed the breastfeeding knowledge and attitude of pregnant women about breastfeeding. A descriptive cross-sectional study was conducted on 120 pregnant women from four primary health-care centers in Erbil City/Iraqi Kurdistan from March 15, 2017, to May 15, 2017. A structured questionnaire was developed based on the evidence in the literature. A face to face interview technique was used for data collection. Overall, $61.7 \%$ of mothers had a poor level of knowledge of breastfeeding despite having a positive attitude $(96.7 \%)$. There was a significant association between mothers' knowledge and mothers' education level, age, occupation, and type of family. However, no significant association was found between mothers' attitude and their education level, age, occupation, parity, type of family, and having the plan to breastfeed. As general, the highest percentage of correct responses was about knowing about early skin-to-skin contact $(69.2 \%)$, initiation of breastfeeding $(57.5 \%)$, knowing the colostrum $(76.7 \%)$, necessity of giving colostrum $(79.2 \%)$, no necessity prelacteal feeding $(79.2 \%)$, exclusive breastfeeding age $(69.2 \%)$, complementary age food $(70.8 \%)$, and optimal weaning time $(70 \%)$ while the lowest percentage of correct responses was about breastfeeding benefits for infant and mother; as well as the contraindication of breastfeeding. Having good attitude regarding breastfeeding is not ensuring to have good knowledge. A significant number of pregnant mothers had not sufficient knowledge that indicating the necessity of interventional programs by the health system.

Keywords: Attitude; Breastfeeding; Knowledge; Pregnant women

\section{INTRODUCTION}

Breastfeeding is feeding of an infant or a young child from the mother's breast milk (Mbada et al., 2013). The decision to breastfeed is influenced by both the knowledge and attitude of mothers toward breastfeeding (Leshi et al., 2016). Some mothers have inadequate knowledge regarding the benefits and importance of breastfeeding that result in not practicing (Mahmud, 2011). Furthermore, positive maternal attitudes toward breastfeeding are associated with continuing longer breastfeeding and have a higher chance of success. On the contrary, negative views of women toward breastfeeding are considered to be a significant barrier to initiate and continue to breastfeeding (Vijayalakshmi et al., 2015).

The World Health Organization (WHO) and the United Nations International Children's Emergency Fund (UNICEF) recommend that breastfeeding be initiated within the $1^{\text {st }} \mathrm{h}$ after birth, be continued exclusively for the first 6 months of life and continued with safe and adequate complementary foods, up to 2 years or beyond
(D. UNICEF, 2005). Globally, a minority of infants and children meet these recommendations: Only 44\% of infants initiate breastfeeding within the $1^{\text {st }} \mathrm{h}$ after birth and $40 \%$ of all infants under 6 months of age are exclusively breastfed. At 2 years of age, $45 \%$ of children are still breastfeeding (World Health Organization, 2018).

Geneva Infant Feeding Association's report (IBFANGIFA) (2015), in a general overview of breastfeeding in Iraq, indicates that the rate of early initiation of breastfeeding passed from $25.1 \%$ in 2006 to $43 \%$ in 2011. While representing a significant increase, this means that almost six children out of ten are still not receiving any breast milk during their $1^{\text {st }} \mathrm{h}$ of life. Even though, delayed breastfeeding is proven to have a negative impact on neonatal mortality (Network, 2017). In addition, the rate of continuous breastfeeding at 2 years dropped from $35.7 \%$ in 2006 to $23 \%$ in 2011 with a high rate of bottle feeding (64\%) (Network, 2017). Furthermore, the rate of exclusively breastfeeding in Iraqi babies under 6 months was $25.1 \%$ in 2006 and only $20 \%$ in 2011 (WHO, 2016). 
Multiple Indicator Cluster Survey (2011) reveals that the rate of early initiation of breastfeeding was 37.8\% in the Kurdistan Region (WHO, 2016) while the rate of breastfeeding initiation within the $1^{\text {st }} \mathrm{h}$ after delivery in Iraq 2011 was 42.8\% (UNICEF and WHO, 2018).

According to research carried out in Erbil City in 2010, only $17.5 \%$ of mothers knew that breastfeeding should be initiated during the $1^{\text {st }} \mathrm{h}$ after delivery, and $40.4 \%$ of mothers did not know the importance of colostrum for a newborn. Besides, $41.1 \%$ of mothers did not know that a child needs 6 months of exclusive breastfeeding (Al-Azzawi et al., 2010).

Indeed, the knowledge of mothers about breastfeeding is very important. During the pregnancy, a mother should get ready to breastfeed her baby, and this is a critical time to acquire information and to increase knowledge about breastfeeding. Authorities, physicians, and other sections of the health-care departments are responsible for providing information for pregnant mothers about all breastfeeding aspects and prepare them to make a decision (Karimi et al., 2014).

Although some studies have assessed knowledge, attitude and practice of breastfeeding in different cities of Kurdistan Region and several efforts taken by the government in this regard, still understanding the current breastfeeding knowledge and attitudes of mothers is very important to develop appropriate intervention strategies to meet the WHO and UNICEF recommendation in Kurdistan Region. Therefore, the present study was undertaken to assess breastfeeding knowledge and attitude of pregnant women in Erbil City, the capital of Iraqi Kurdistan.

The objectives of this study were to assess the knowledge of pregnant women regarding breastfeeding, the attitude of pregnant women regarding breastfeeding, and to find out the association between mothers' knowledge and attitude regarding breastfeeding with demographic characteristics.

\section{SUBJECTS AND METHODS}

A descriptive cross-sectional study was undertaken on the pregnant women of four primary health-care centers (PHCCs) in Erbil City, the capital of Iraqi Kurdistan.

The settings of the study were Zhian in North, Sarkarez in South, Mala Afendi in East, and Muhammad Bajalan in West. The data collection was performed from March 15, 2017, to May 15, 2017.

Multistage random sampling was used to select 120 pregnant women who attended the PHCCs for prenatal care. In the first stage of sampling, all the PHCCs in Erbil city in four geographic areas were included. In the second stage, four PHCCs from each geographic area were randomly selected. In the third stage, 30 subjects from each PHCC were recruited in the study.

\section{Inclusion and Exclusion Criteria}

The subjects who were included in this study were Kurdish pregnant women in the second-and third-trimester and aged 18 years and older. The subjects were selected irrespective of sociodemographic perspectives. Those patients who did not present the consent were not included in the study.

\section{Ethical Considerations}

The protocol of the study was approved by the Scientific and Ethical Committee of College of Nursing/Hawler Medical University. Besides, formal permission was taken from each PHCC. Data were collected from mothers who agreed to participate in the study. The required information was explained to all patients. Participation was voluntary and anonymous, and their right to withdraw from the survey was protected. The verbal consent was obtained from all study participants. Furthermore, the confidentiality of all personal information of the study sample was protected throughout the study period.

\section{Measurement Tools}

A structured questionnaire was developed based on the evidence of the literature. The information required was collected through a face-to-face interview technique. The questionnaire consisted of three parts.

Part A: A list of nine items that covered the mother's demographic data.

Part B: Mothers' knowledge regarding breastfeeding consisted of four aspects: First aspect: Information about the recommendations of WHO and UNICEF was included in the study. The information was about breastfeeding for optimal infant feeding that had eight questions. Second aspect: Benefits of breastfeeding for the infant (nine items). Third aspect: Benefits of breastfeeding for mothers (seven items). Fourth aspect: Contraindication of breastfeeding (one items).

Responses to the knowledge questions were categorized as correct or incorrect. A score of 1 point was given for each correct response and zero for any incorrect or "do not know" replies for each question. The total score was calculated by summing the individual score of 25 knowledge questions ranged 1-25. The level of the knowledge scores regarding breastfeeding was categorized into three levels as follows: (1) Poor level of knowledge included score 0-10 points; (2) fair level of knowledge included score 11-20 
points; and (3) good level of knowledge included score 21-25 points.

Part C: Mothers' attitude toward breastfeeding contains 27 questions. A three-point Likert scale ranging from 1 (disagree), 2 (neutral), to 3 (agree) was applied for the attitude and a reverse-scored for 14 questions which were presented negatively. The scores were summed to obtain total attitude scores ranged 27-81; higher scores reflected that participants had a more positive attitude toward breastfeeding. Total scores were grouped into the following three categories: Positive attitude (65-81 scores), neutral attitude (41-64 scores), and a negative attitude (27-40 scores).

For the validity of the questionnaire, it was reviewed by a panel of 12 experts from different specialties. Members of the panel checked and made comments on the questionnaire individually. Then, the questionnaire was adjusted by the researcher and approved by most of the members in the panel. For reliability of the questionnaire, a pilot study was carried out for ten pregnant women from March 1, 2017, to March 10, 2017, that excluded from the original sample of the study using Cronbach's alpha, reliability was calculated at 0.83 .

\section{Statistical Methods}

Data were coded and entered into a computer using the Statistical Package for the Social Sciences (SPSS version 24:0) for analysis. Percentage and frequencies were used for categorical variables, and the Chi-square test was used to indicate the significant relationship between mothers' knowledge, attitude, and mothers' some background information. The significant level was determined in $P \leq 0.05$.

\section{RESULTS}

\section{Demographic Data of Study Participants}

The mean age of the participants was 25.68 (SD: 5.69 years). The study revealed that $73.3 \%$ of mothers were in the age group of $21-35$ years old and $15.9 \%$ were illiterate, $20.8 \%$ (primary school graduates), 19.2\% (intermediate school graduates), 16.6\% (secondary school graduates), and $27.5 \%$ had institute education and above. The majority of the participants were unemployed (86.7\%) and $54.2 \%$ of them lived in a nuclear family. Furthermore, $41.7 \%$ of the study sample were primigravida, and $52.5 \%$ of them had no lactation history. Furthermore, most of the study participants (90.8\%) did not receive any breastfeeding instructions during antenatal care and wanted $(71.7 \%)$ to attend the breastfeeding class. The main source of breastfeeding information was their family and relative [Table 1].

\section{Mothers' Knowledge Regarding Breastfeeding}

The highest correct responses were regarding the necessity of giving colostrum and prelacteal feeds $(79.2 \%$ and $79.2 \%$ ), followed by knowing the colostrum, age of complementary food, and optimal time for weaning $(76.7 \%$, $70.8 \%$, and $70.0 \%$, respectively). The information about skin-to-skin contact, the age for exclusive breastfeeding and the best time for initiating breastfeeding after childbirth had a higher correct response $(69.2 \%, 69.2 \%$, and $57.5 \%$, respectively). However, the lowest correct responses were about benefits of breastfeeding for the mother and were save time $(1.7 \%)$, save money $(3.3 \%)$, decreased incidence of ovarian cancer $(4.2 \%)$, and decreased incidence of breast cancer $(33.3 \%)$.

Furthermore, $8.3 \%$ helps the mother's body to return to normal, $9.2 \%$ provides emotional satisfaction to the mother, and $10.0 \%$ leads to uterine involution. Regarding breastfeeding benefits for the infant, $5.8 \%$ of mothers mentioned that breast milk is a ready food, $7.5 \%$ knew that it has the right temperature and it is always clean. Further, $14.2 \%$ of study sample stated that breastfeeding promotes bonding between mother and child, $18.3 \%$ of them believed that breastfeeding provides a perfect and healthy nutrition for baby, $25.8 \%$ of mothers stated that breastfeeding protects baby against infection and illnesses, and only $19.2 \%$ of them knew the contraindications of breastfeeding [Table 2].

\section{Mothers' Attitude Regarding Breastfeeding}

The results of this table revealed that the highly more favorable attitudes toward breastfeeding among the study participants included: Breast milk is the ideal food for babies $(100.0 \%)$, it is more easily digested than formula $(98.3 \%)$, and breastfeeding child is healthier than formula feeding the child $(97.5 \%)$. It is easier than formula feeding (96.7\%), god created breast on mother to feed the baby $(96.7 \%)$, and breastfeeding is a natural process, it should not be neglected $(96.7 \%)$.

Moreover, the majority of the mothers believed that mother expresses her love for her baby through breastfeeding $(88.3 \%)$, breastfeeding is one of the great joys of motherhood (88.3\%). Mother feels guilty for not breastfeeding her kids $(85.0 \%)$, religious background is behind the adoption of breastfeeding (82.5\%), and initiation of breastfeeding within $1 \mathrm{~h}$ of birth is possible $(81.7 \%)$ even though most participants reported that most women have not sufficient milk in the first 6 months $(81.7 \%)$ and when the baby is teething the breastfeeding should be continued (80.8\%).

While the mothers generally disagreed with the statements such as breastfeeding have negative effect on marital 
Table 1: Demographic data of the study participants

\begin{tabular}{|c|c|c|c|}
\hline Mother's information & & Frequency & Percent \\
\hline \multirow[t]{5}{*}{ Mother's age (years) } & $\leq 20$ & 24 & 20.0 \\
\hline & $21-25$ & 39 & 32.5 \\
\hline & $26-30$ & 38 & 31.7 \\
\hline & $31-35$ & 11 & 9.2 \\
\hline & $36-40$ & 8 & 6.6 \\
\hline Mean age & $\bar{x} \pm S D=(25.68 \pm 5.69)$ & & \\
\hline \multirow[t]{6}{*}{ Education level } & Illiterate & 19 & 15.9 \\
\hline & Primary school graduated & 25 & 20.8 \\
\hline & Intermediate school graduated & 23 & 19.2 \\
\hline & Secondary school graduate & 20 & 16.6 \\
\hline & Institute graduated & 17 & 14.2 \\
\hline & College graduated and above & 16 & 13.3 \\
\hline \multirow[t]{2}{*}{ Occupation } & Employed & 16 & 13.3 \\
\hline & Unemployed & 104 & 86.7 \\
\hline \multirow[t]{2}{*}{ Type of family } & Nuclear family & 65 & 54.2 \\
\hline & Extended family & 55 & 45.8 \\
\hline \multirow[t]{2}{*}{ Gravidity } & Primigravida & 50 & 41.7 \\
\hline & Multigravida & 70 & 58.3 \\
\hline \multirow[t]{2}{*}{ Lactation history } & Yes & 63 & 52.5 \\
\hline & No & 57 & 47.5 \\
\hline \multirow[t]{2}{*}{ Receiving breastfeeding instructions in the antenatal care } & Yes & 11 & 9.2 \\
\hline & No & 109 & 90.8 \\
\hline \multirow[t]{2}{*}{ Desire to attendance in breastfeeding class } & Yes & 86 & 71.7 \\
\hline & No & 28 & 23.3 \\
\hline \multirow[t]{4}{*}{ Main source of breastfeeding information } & Family and relative & 63 & 52.5 \\
\hline & Internet & 29 & 24.2 \\
\hline & Mass media & 18 & 15 \\
\hline & Health-care provider & 10 & 8.3 \\
\hline
\end{tabular}

Table 2: Mothers' knowledge regarding breastfeeding

\begin{tabular}{|c|c|c|c|}
\hline \multirow[t]{2}{*}{ Domains } & \multirow[t]{2}{*}{ Items } & \multicolumn{2}{|c|}{ Correct answers } \\
\hline & & $\mathbf{F}$ & $\%$ \\
\hline \multirow[t]{9}{*}{ Benefits of breastfeeding for the infant } & Provides perfect and healthy nutrition & 22 & 18.3 \\
\hline & Protects against infection and illnesses & 31 & 25.8 \\
\hline & Promotes bonding between mother and child & 17 & 14.2 \\
\hline & Strengthen the child's bones & 18 & 15.0 \\
\hline & Enhances development & 49 & 40.8 \\
\hline & Enhances intelligence & 29 & 24.2 \\
\hline & Has the right temperature & 9 & 7.5 \\
\hline & It is always clean & 15 & 12.5 \\
\hline & It is ready & 7 & 5.8 \\
\hline \multirow[t]{7}{*}{ Benefits of breastfeeding for the mother } & Leads to uterine involution & 12 & 10.0 \\
\hline & Decrease the incidence of the breast & 40 & 33.3 \\
\hline & Decrease the incidence of ovarian cancer & 5 & 4.2 \\
\hline & Helps the mother's body to return to normal & 10 & 8.3 \\
\hline & Provides emotional satisfaction to the mother & 11 & 9.2 \\
\hline & Save time & 2 & 1.7 \\
\hline & Save money & 4 & 3.3 \\
\hline \multirow[t]{8}{*}{ WHO and UNICEF recommendation } & Knowing about early skin-to-skin contact & 83 & 69.2 \\
\hline & Best time for initiating breastfeeding & 69 & 57.5 \\
\hline & Knowing the colostrum & 92 & 76.7 \\
\hline & The necessity of giving colostrum & 95 & 79.2 \\
\hline & Necessity of giving prelacteal feeds & 95 & 79.2 \\
\hline & Age for exclusive breastfeeding & 83 & 69.2 \\
\hline & Age of complementary food & 85 & 70.8 \\
\hline & The optimal time for weaning & 84 & 70.0 \\
\hline Breastfeeding contraindications & Knowing the contraindications of breastfeeding & 23 & 19.2 \\
\hline
\end{tabular}


relationship (71.7\%), breastfeeding causes the mother to have an unpleasant odor (68.3\%), mother feels fear of distorted breast shape by breastfeeding $(66.7 \%)$, fathers feel left out if a mother breastfeeds $(65.0 \%)$, mother dislikes breastfeeding because it is time taking (64.2\%). In addition, other factors who subjects disagreed were: Difficult for breastfeeding mother to take care of her family $(63.3 \%)$, size of the breast has an effect on producing sufficient breast milk $(60.0 \%)$, women should not breastfeed in public places (53.3\%), and most women have not adequate milk in the first 6 months (49.2\%); nowadays, breastfeeding is becoming old-fashioned $(41.7 \%)$, breastfeeding makes mother be thin (42.5\%), formula fed babies are more likely to be overfed than breastfed babies $(30.0 \%)$, formula feeding is the better choice if a mother plans to work outside the home $(30.8 \%)$, and community prefers formula feeding over breastfeeding $(25.8 \%)$ [Table 3].

\section{Level of Knowledge and Attitude of Participants}

The study found that $61.7 \%$ of the study participants had poor knowledge and $38.3 \%$ had fair knowledge. The highest percentage of the subjects $(96.7 \%)$ had positive attitudes toward breastfeeding [Table 4].
Association between Mothers' Knowledge and Attitude Regarding Breastfeeding with Demographic Characteristic

There was a highly significant association between mothers' knowledge and mothers' education level, as well as a significant association between mothers' knowledge and mothers' age, occupation, and type of family. However, no significant association was found between mothers' attitude and mothers' education level, age, occupation, parity, type of family, and having the plan to breastfeed [Table 5].

\section{DISCUSSION}

\section{Breastfeeding Knowledge and Attitudes}

One of the main causes of neonatal mortality and morbidity is inadequate breastfeeding (Manoj et al., 2018). Inadequate knowledge, poor attitude, or inappropriate practice of breastfeeding may lead to undesirable consequences on both mother and child (Kumar et al., 2014). Mother's knowledge and skills can increase the rate and duration of breastfeeding and are relevant components of effective decisions and actions for breastfeeding (Cardoso et al., 2017; Chaudhary et al., 2011; Dyson et al., 2005).

Table 3: Mothers' attitude regarding breastfeeding

\begin{tabular}{|c|c|c|c|c|c|c|}
\hline \multirow[t]{2}{*}{ Items } & \multicolumn{2}{|c|}{ Agree } & \multicolumn{2}{|c|}{ Neutral } & \multicolumn{2}{|c|}{ Disagree } \\
\hline & $\mathbf{F}$ & $\%$ & $\mathbf{F}$ & $\%$ & $\mathbf{F}$ & $\%$ \\
\hline 1. God created breast on the mother to feed the baby & 116 & 96.7 & 4 & 3.3 & 0 & 0 \\
\hline 2. Breastfeeding is a natural process, it should not be neglected & 118 & 98.3 & 1 & 0.8 & 1 & 0.8 \\
\hline 3. Religious background is behind adoption of breastfeeding & 99 & 82.5 & 11 & 9.2 & 10 & 8.3 \\
\hline 4. Mother expresses her love for her baby through breastfeeding & 106 & 88.3 & 7 & 5.8 & 7 & 5.8 \\
\hline 5. Mother feels guilty for not to breastfeeding some of the kids & 102 & 85.0 & 10 & 8.3 & 8 & 6.7 \\
\hline 6. Breastfeeding is one of the great joys of motherhood & 106 & 88.3 & 11 & 9.2 & 3 & 2.5 \\
\hline 7. *Fathers feel left out if a mother breastfeeds & 14 & 11.7 & 28 & 23.3 & 78 & 65.0 \\
\hline 8. *Breastfeeding has negative effect on marital relationship & 6 & 5.0 & 28 & 23.3 & 86 & 71.7 \\
\hline 9. *Nowadays breastfeeding is becoming old-fashioned & 59 & 49.2 & 11 & 9.2 & 50 & 41.7 \\
\hline 10. *Women should not breastfeed in public places such as restaurants & 48 & 40.0 & 8 & 6.7 & 64 & 53.3 \\
\hline 11. * Formula feeding is the better choice if a mother plans to work outside the home & 48 & 40.0 & 35 & 29.2 & 37 & 30.8 \\
\hline 12. *Community prefers formula feeding over breastfeeding & 74 & 61.7 & 15 & 12.5 & 31 & 25.8 \\
\hline 13. *Mother feels fear of distorted breast shape by breastfeeding & 33 & 27.5 & 7 & 5.8 & 80 & 66.7 \\
\hline 14. *Breastfeeding makes the mother be thin & 45 & 37.5 & 24 & 20.0 & 51 & 42.5 \\
\hline 15. *Breastfeeding causes the mother to have an unpleasant odor & 16 & 13.3 & 22 & 18.3 & 82 & 68.3 \\
\hline 16. *Size of the breast affects producing sufficient breast milk & 23 & 19.2 & 25 & 20.8 & 72 & 60.0 \\
\hline 17. Initiation of breastfeeding within $1 \mathrm{~h}$ of birth is possible if the mother is at a normal situation & 98 & 81.7 & 12 & 10.0 & 10 & 8.3 \\
\hline 18. Even the mother does not have sufficient milk the breastfeeding should be continued & 98 & 81.7 & 10 & 8.3 & 12 & 10.0 \\
\hline 19. When the baby is teething the breastfeeding should be continued & 97 & 80.8 & 8 & 6.7 & 15 & 12.5 \\
\hline 20. Breast milk is the ideal food for babies & 120 & 100.0 & 0 & 0 & 0 & 0 \\
\hline 21. Breastfeeding is easier than formula feeding & 116 & 96.7 & 2 & 1.7 & 2 & 1.7 \\
\hline 22. Breast milk is more easily digested than formula & 118 & 98.3 & 2 & 1.7 & 0 & 0 \\
\hline 23. Breastfeeding a child is healthier than formula feeding child & 117 & 97.5 & 1 & 0.8 & 2 & 1.7 \\
\hline 24. *Mother dislikes breastfeeding because it is time taking & 22 & 18.3 & 21 & 17.5 & 77 & 64.2 \\
\hline 25. *It is difficult for a breastfeeding mother to take care of her family & 29 & 24.2 & 15 & 12.5 & 76 & 63.3 \\
\hline 26. *Formula fed babies are more likely to be overfed than breastfed babies & 60 & 50.0 & 24 & 20.0 & 36 & 30.0 \\
\hline 27. *Most women have not sufficient milk in the first 6 months & 24 & 20.0 & 37 & 30.8 & 59 & 49.2 \\
\hline
\end{tabular}

${ }^{\star}$ Reverse scored item 
Table 4: Level of mother's knowledge and attitude

\begin{tabular}{llcc}
\hline Item & Level & Frequency & Percent \\
\hline Knowledge & Poor & 74 & 61.7 \\
& Fair & 46 & 38.3 \\
Attitude & Positive & 116 & 96.7 \\
& Neutral & 4 & 3.3 \\
\hline
\end{tabular}

Table 5: The association between mothers' knowledge and attitude regarding breastfeeding and demographic characteristic

\begin{tabular}{lcc} 
Variable & $\begin{array}{c}\text { Mothers' knowledge } \\
\text { of breastfeeding }\end{array}$ & $\begin{array}{c}\text { Mothers' attitude } \\
\text { toward breastfeeding }\end{array}$ \\
\cline { 2 - 3 } Age & $\boldsymbol{P}$ value & $\mathbf{P}$ value \\
\hline Educational level & 0.004 & 0.079 \\
Occupation & 0.001 & 0.079 \\
Parity & 0.043 & 0.290 \\
Type of family & 0.052 & 0.165 \\
Having plan for & 0.024 & 0.208 \\
breastfeeding & 0.058 & 0.032 \\
\hline
\end{tabular}

Concerning the effect of knowledge on breastfeeding, several studies reported that poor maternal knowledge was a risk factor for breastfeeding abandonment (Brand et al., 2011; Chambers et al., 2007; Laanterä et al., 2010; Zhou et al., 2010). Fortunately compared with previous local (Al-Azzawi et al., 2012; UNICEF and WHO, 2018) and international studies (Jiang et al., 2012; Mehwish et al., 2017). The present study showed that the majority of mothers were familiar and knowledgeable toward the recommendations of WHO and UNICEF about breastfeeding.

The most mothers of this study had to lack knowledge concerning the benefits of breastfeeding for baby and mother, and this finding contrasts with the results of studies from India, Saudi Arabia, and Portugal, which found that mothers were knowledgeable about breastfeeding benefits (Cardoso et al., 2017; Orabi et al., 2017; Richa and Umesh, 2012).

The current study indicated that the highest percentage of pregnant women had poor knowledge about breastfeeding, but they had a positive attitude. Their positive perspective of attitude toward breastfeeding was a desirable result that might be due to the religious context and highly motivated Kurdish culture toward breastfeeding issues. Islam religion advises the mothers that they shall give suck to their children for 2 full years (Saleh and Kerr, 1996).

A recent Indian study reported that mother's knowledge and attitude toward breastfeeding was favorable (Manoj et al., 2018). A study from Yemen reported that mothers have inadequate knowledge and neutral attitude toward breastfeeding (Dallak et al., 2016) in contrast with good knowledge with a neutral attitude regarding breastfeeding in Saudi Arabia (Orabi et al., 2017).
The results of this study reflect a wide gap between the breastfeeding knowledge of Kurdish mothers and their attitudes toward breastfeeding. The gap might be due to the low educational level since more than half of the subjects had less than secondary educational level. Afrose et al. reported that a secondary level of mother's education seems to be directly related to good knowledge toward breastfeeding (Afrose et al., 2012). Besides, despite the desire of most of the subjects about breastfeeding class, only a small portion of them received breastfeeding instructions from health-care providers during prenatal visits. It seems that women do not have access to formal and standard breastfeeding education and counseling in the PHCCs in this region.

The frequent sources of breastfeeding information of the women were their family and relatives. The education of a mother seemed to directly have an impact on its child life. More educated mothers use more health services, provide better care for children, and have good knowledge of their child's proper feeding (Afrose et al., 2012). It is evident that education is a key factor for mothers' knowledge of breastfeeding (Karimi et al., 2014).

In the present study, participants had poor knowledge of breastfeeding with a positive attitude. Despite supporting the opinion that the quantity of knowledge is associated with consistency of attitude-behavior, but there is no definite evidence that knowledge has a causal influence on the consistency of attitude-behavior. Assessment of the attitude based on little knowledge may be a poor predictor of subsequent behavior due to the continuous changes in individuals' attitudes, while high-knowledge attitudes are more likely to be stable between evaluation time and behavior time. The perspective of attitude inferences suggests the attitudes that differ in knowledge might still differ in their impacts (Fabrigar et al., 2006).

In contrast with the no significant association of the knowledge with attitudes in this study, Afrose et al. AL-Abedi claimed a significant association of maternal education with her breastfeeding knowledge. Other studies have reported similar results (Afrose et al., 2012; Al-Hially, 2010).

\section{Limitations of the Study}

The findings reported in the present survey may not reflect the exact situation in the rest of the country since only one setting was included in this study. The subjects in other settings may have different knowledge and attitudes about breastfeeding. In addition, the small sample size may preclude us from generalizing the study findings. 


\section{CONCLUSIONS AND RECOMMENDATIONS}

The present study suggests that despite good attitudes of mothers to breastfeeding, their level of knowledge was not sufficient. A significant association was found between the level of knowledge and sociodemographic aspects, but not with attitudes. It is recommended that pregnant women need to be educated about the benefits of breastfeeding during screening and antenatal care. In this regard, the convenient booklets about breastfeeding could be prepared, designed, and distributed on pregnant women.

\section{ACKNOWLEDGMENTS}

The authors of the study would like to present their deep thanks to the all PHCCs (Zhian, Sarkarez, Mala Afendi, and Muhammad Bajalan) in Erbil city and its staff for their kind cooperation and assistance.

\section{CONFLICTS OF INTEREST}

The authors declare that they have no conflicts of interest.

\section{FUNDING}

This study is authors-based funded.

\section{REFERENCES}

Afrose, L., B. Banu, K. R. Ahmed and K. Khanom. 2012. Factors associated with knowledge about breastfeeding among female garment workers in Dhaka city. WHO South East Asia J. Public Health. 1(3): 249.

Al-Azzawi, D., H. D. Kareema and D. Shaker. 2010. Assessment of breastfeeding knowledge among mothers in Erbil city. Zanco J. Med. Sci. 14(2): 1-6.

Al-Azzawi, S. I., K. A. Hussein and N. Z. Shaker. 2012. Knowledge, attitude and practices (KAP) of mothers toward infant and young child feeding in primary health care (PHC) centers, Erbil city. Kufa J. Nurs. Sci. 2(2): 118-126.

Al-Hially, Y. A. 2010. Assessment of mothers' knowledge about breastfeeding and determining predictors. Med. J. Tikrit. 2(162): 77-83.

Brand, E., C. Kothari and M. A. Stark. 2011. Factors related to breastfeeding discontinuation between hospital discharge and 2 weeks postpartum. J. Perinat. Educ. 20(1): 36-44.

Cardoso, A., A. P. e Silva and H. Marín. 2017. Pregnant women's knowledge gaps about breastfeeding in northern Portugal. Open J Obstetr. Gynecol. 7(03): 376.

Chambers, J. A., E. Alder, P. Hoddinott and R. Mclnnes. 2007. A systematic review of measures assessing mothers' knowledge, attitudes, confidence and satisfaction towards breastfeeding. Breastfeed. Rev. 15(3): 17.

Chaudhary, R., T. Shah and S. Raja. 2011. Knowledge and practice of mothers regarding breast feeding: A hospital based study. Health Renaiss. 9(3): 194-200.
Dallak, A., N. Al-Rabeei and Y. Aljahmi. 2016. Breastfeeding knowledge, attitude, and practices among mothers attending health centers in Sana'a city. ARC J. Public Health Community Med. 1(2): 9-17.

Dyson, L., F. M. McCormick and M. J. Renfrew. 2005. Interventions for promoting the initiation of breastfeeding. Cochrane Database Syst. Rev. 2: CD001688.

Fabrigar, L. R., R. E. Petty, S. M. Smith and Jr S. L. Crites. 2006. Understanding knowledge effects on attitude-behavior consistency: The role of relevance, complexity, and amount of knowledge. J. Pers. Soc. Psychol. 90(4): 556.

International Baby Food Action Network. 2017. The Convention on the Rights of the Child: Report on the Situation of Infant and Young Child Feeding in Bahrain. IBFAN.

Jiang, H., M. Li, D. Yang, L. M. Wen, C. Hunter, G. He and X. Qian. 2012. Awareness, intention, and needs regarding breastfeeding: Findings from first-time mothers in Shanghai, China. Breastfeed. Med. 7(6): 526-534.

Karimi, B., M. Z. Sani, R. Ghorbani and N. Danai. 2014. The pregnant mothers' knowledge about breastfeeding in Semnan, Iran. Middle East J. Rehabil. Health. 1(1): e20833.

Kumar, L., K. Shahnawaz, G. Varma, S. K. Choudhary, A. Gupta and J. B. Singh. 2014. Knowledge, attitude and practices of nourishing mothers about breast feeding, attending urban health centre: A cross-sectional study from Kishanganj, Bihar. J Evol. Med. Dent. Sci. 3(7): 1681-1690.

Laanterä, S., A. M. Pietilä and T. Pölkki. 2010. Knowledge of breastfeeding among pregnant mothers and fathers. J. Perinat. Neonatal Nurs. 24(4): 320-329.

Leshi, O., F. O. Samuel and M. O. Ajakaye. 2016. Breastfeeding knowledge, attitude and intention among female young adults in Ibadan, Nigeria. Open J. Nurs. 6(01): 11.

Mahmud, N. A. 2011. Knowledge of Breastfeeding: A descriptive study among mothers in Kirkuk Governorate. Nurs Natl. Iraqi Specility. 24(2): 84-93.

Manoj, N. K. A., A. Mithrason and V. Thomas. 2018. Knowledge, attitude and determinants of breastfeeding among antenatal women at a teaching hospital at Wayanad, Kerala: A crosssectional study. Int. J. Med. Paediatr. Oncol. 4: 98-103.

Mbada,C.E.,A.E. Olowookere, J.O.Faronbi, F.C.Oyinlola-Aromolaran, F. A. Faremi, A. O. Ogundele, T. O. Awotidebe, A. A. Ojo and O. A. Augustine. 2013. Knowledge, attitude and techniques of breastfeeding among Nigerian mothers from a semi-urban community. BMC Res. Notes. 6(1): 552.

Mehwish, H. H., K. Mannan, S. Saleem, F. Rehman, U. Fatima and A. K. Khan. 2017. Knowledge and attitude about breastfeeding among lactating mothers of rural Punjab. Pak. J. Med. Health Sci. 11(3): 1114-1117.

Orabi, A., R. al-Sayad and K. Alharthi. 2017. Investigating the knowledge, attitudes, practices and perceived barriers of breast feeding among saudi women in the national guard hospital Jeddah. Athens J. Health. 4: 257.

Richa, N. and S. Umesh. 2012. Assessment of knowledge and attitude of antenatal mothers towards breastfeeding. Natl. J. Community Med. 3: 381-384.

Saleh, M. and M. Kerr. 1996. Understanding the Muslim patient. J. SOGC. 18(1): 55-64.

UNICEF and WHO. 2018. Capture the Moment Early Initiation of Breastfeeding: The Best Start for Every Newborn. UNICEF, New York. Available from: https://www.who.int/ nutrition/publications/infantfeeding/capture-moment-earlyinitiation-bf/en. [Last accessed on Accessed 20 Jun 2018]. 
UNICEF DATA. 2005. Monitoring the Situation of Children and Women. Multiple Indicator Cluster Survey Manual. UNICEF, New York.

Vijayalakshmi, P., T. Susheela and D. Mythili. 2015. Knowledge, attitudes, and breast feeding practices of postnatal mothers: A cross sectional survey. Int. J. Health Sci. 9(4): 364.

WHO. 2016. Global Strategy for Women's, Children's and Adolescents' Health. Available from: http://www.apps.who.int/gho/data/node. main.GSWCAHDATA?lang=en. [Last accessed on Accessed 20 Jun 2018].
World Health Organization. 2018. Implementation Guidance: Protecting, Promoting and Supporting Breastfeeding in Facilities Providing Maternity and Newborn Services: The Revised Baby-friendly Hospital Initiative. World Health Organization, Geneva.

Zhou, Q., K. M. Younger and J. M. Kearney. 2010. An exploration of the knowledge and attitudes towards breastfeeding among a sample of Chinese mothers in Ireland. BMC Public Health. 10(1): 722. 